\title{
A representação da escravidão "negro" no Brasil através de Imagens explícitas nos livros didáticos dos $6^{\circ} \mathrm{s}$ anos.
}

(The representation of "black" slavery in Brazil through explicit images in the textbooks of the 6th years.)

Sueli da Cunha

Escola Estadual de Minas Gerais.

Fecha recepción: 01-10-2017

Páginas 224-238

Fecha aceptación: 01-12-2017

\section{Resumo.}

O artigo é um recorte da pesquisa de mestrado o qual buscou uma análise das representações do negro no Brasil, por meio de imagens explicitas contidas nos livros didáticos dos $6^{\circ} \mathrm{s}$ anos da escola Monsenhor Antônio José Ferreira-MG. Ainda, Identificar a maneira pela qual a história do Brasil foi retratada no Brasil; Averiguar como se deu a participação dos chamados heróis nacionais; Observar o grau de importância dos negros, brancos e índios; Verificar a forma de que os negros aparecem nos livros didáticos das escolas textos e, ou ilustrações. A pesquisa se apropriou do método qualitativo do tipo descritivo com análise documental "o livro didático dos $6^{\circ} \mathrm{s}$ anos. Contudo, denota-se ainda ideologías que expressam o racismo, de forma explícita pela forma pela qual é retratado como inferioridade, comprado como mercadoria, passando a imagem como de um animal forte para o trabalho.

Palabas clave: discriminação; negro; livro; didático; preconceito

\section{Abstract.}

The article is a cut of the master's research which sought an analysis of the representations of the Negro in Brazil, through explicit images contained in the textbooks of the 6th grade of the Monsenhor Antônio José Ferreira-MG school. Also, Identify the way in which the history of Brazil was portrayed in Brazil; To find out how the participation of so-called national heroes took place; Observe the degree of importance of blacks, whites and Indians; Check how blacks appear in school textbooks and texts, or illustrations. The research appropriated the qualitative method of the descriptive type with documentary analysis "the 6th grade textbook. However, there are also ideologies that express racism, explicitly for the way in which it is portrayed as inferiority, bought as merchandise, passing the image as a strong animal for work.

Keywords: discrimination; black; book; didactic; preconception 


\section{1.-Introdução.}

A identidade brasileira possui características de diferentes influências culturais que auxiliaram na formação do povo brasileiro. 0 desenvolvimento da história brasileira se deu a partir da cultura e dos povos de diversos continentes Africano, Asiático, Europeu e Americano. Apesar dessas culturas diferentes se adaptarem ao Brasil, a mais valorizada foi a européia. Assim, a educação e a cultura do país seguiram 0 modelo de organização implantado pelos portugueses (Fernandes, 2005).

Apesar da formação histórico-social comprovar a nossa diversidade cultural, ainda, identificou dificuldades da escola brasileira de conviver com tal realidade sendo que as instituições de ensino ainda "não sabem trabalhar com as crianças e jovens dos estratos sociais mais pobres, constituídos, na sua grande maioria, de negros e mestiços" (Fernandes, 2005, p. 380).

Deste modo, o estudo elencou alguns questionamentos: Como os livros didáticos "História" demonstram a historiografia brasileira? Como se deu a participação dos chamados heróis nacionais? É dado o mesmo grau de importância a negros, brancos e índios? Quando os negros aparecem nos livros didáticos das escolas públicas estes por meio de textos e, ou ilustrações, são retratados de forma?

O objetivo Geral buscou uma análise as imagens do negro nos livros didáticos da disciplina História, livro (Estudar História: das origens do homem à era digital) dos $6^{\circ} \mathrm{s}$ anos do Ensino Fundamental, autora (Braic, 2011).

Na sequência, os objetivos específicos buscaram: Identificar a maneira pela qual a história do Brasil vem sendo retratada no Brasil; Averiguar como se deu a participação dos chamados heróis nacionais; Observar se vem sendo dado o mesmo grau de importância a negros, brancos e índios; Verificar a maneira eu os negros foram ilustrados nos livros didáticos dos $6^{\circ} \mathrm{s}$ anos.

O estudo se justifica devido ao aumento da democratização do ensino no Brasil onde - Governo passou a oferecer materiais (livros didáticos) como contribuição para a melhoria do processo ensino aprendizagem nas escolas, os quais antes passam pela classificação de qualidade do Ministério da Educação (MEC). No entanto, percebe-se que a imagem social dos negros continuam associadas a situações de menor prestígio sob o âmbito social, ocasionando assim maior dificuldade para o negro de se afirmar na sociedade brasileira como um cidadão com direitos e deveres igualitários.

\section{2.-O Negro no Livro Didático.}

Entretanto, as instituições no processo do ensino são espaço de reflexão e acolhimento das diferenças, por isso, a escola torna-se capaz de desfazer os desequilíbrios que são causados nesse ambiente, repensando os preconceitos que ali existem. Ao deixar de valorizar a cultura afro-brasileira a construção de identidades sofreu uma grande rejeição de diversos elementos por ela constituídos. 
De tal maneira, quando a escola trabalha essa diversidade o projeto deve ser considerado em favor da instituição, para que seu currículo não venha a ignorar a população atendida.

Na segunda metade do século XX, através dos movimentos sociais ocorreram reivindicações realizadas por meio de forte pressão política com 0 intuito de diminuírem o tratamento discriminatório que recebiam no seu cotidiano. Destaca-se nesse cenário o movimento social negro que lutava pela obtenção do reconhecimento das matrizes africanas na formação da cultura brasileira.

Durante a realização da Convenção Nacional do Negro pela Constituinte, realizada em Brasília nos dias 26 e 27 de agosto de 1986 com a participação de mais de 185 delegados de todo o país, intelectuais e ativistas afrodescendentes reivindicaram medidas afirmativas a favor do legado da população negra.

Na figura abaixo uma reportagem da Folha de São Paulo sobre as reivindicações propostas pelo movimento negro à constituinte em 1986.

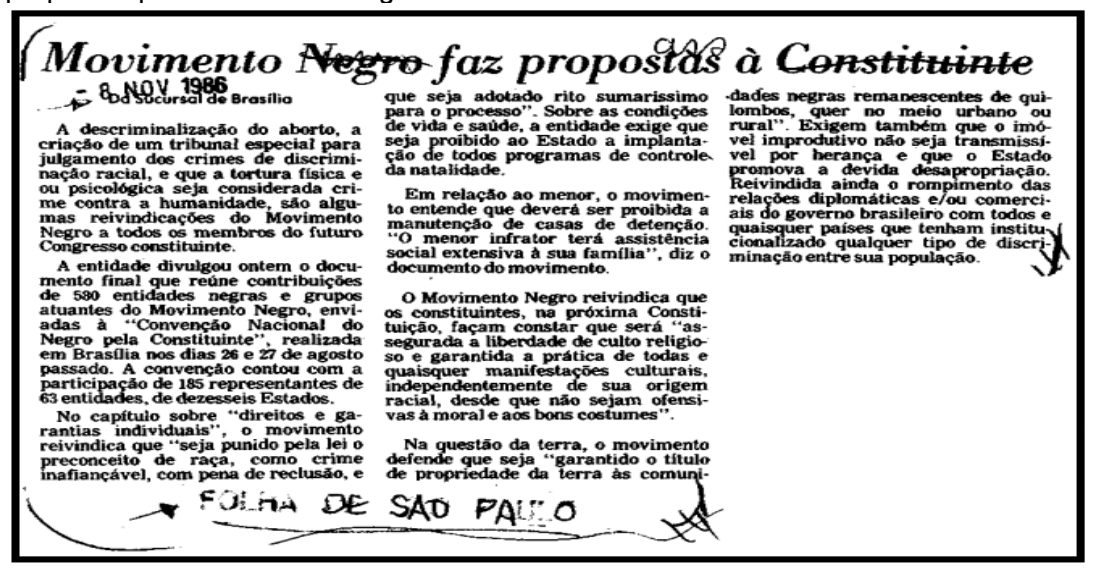

Fonte: Folha de São Paulo: Reivindicações Movimento Negro (1986).

Dentre as reivindicações havia o estudo das origens africanas e a valorização de tal cultura por toda a população brasileira. Assim, em Educação antirracista: caminhos abertos pela Lei Federal no 10.639/03 encontra-se a seguinte afirmação "o processo educacional respeitará todos os aspectos da cultura brasileira. É obrigatório a inclusão nos currículos escolares de I, II e III graus, do ensino da História da África e da História do Negro no Brasil" (2005, p. 236).

Partiu de denúncias de violência e desigualdade racial, tais movimentos foram capazes de provocar debates relacionados ao questionamento das diferenças culturais existentes no país onde a maior parte dos saberes que formam a respectiva população possui origens no passado das civilizações africanas. As lutas, exigem a necessidade de legitimação, "uma Lei" que inclua a obrigatoriedade do estudo das raízes africanas, ainda desconhecido na história do Brasil e na educação e no processo ensino aprendizagem (Azevedo, 2011, p. 3). 
Ana Célia da Silva considerava que: Os currículos, programas, materiais e rituais pedagógicos privilegiam os valores europeus em detrimento dos valores de outros grupos étnico-raciais presentes na sociedade. Os valores desses grupos são, na maioria das vezes, ocultados ou apresentados de uma forma tal que não coloque em conflito os valores dominantes. Em consequência, as populações excluídas, podem vir a privilegiar os valores da história e cultura oficial como os únicos a serem considerados, renegando os seus próprios valores, se o processo pedagógico, o seu cotidiano e a sua cultura, não favorecer lhes oportunidades de reflexão e reelaborarão (Silva, 2001, p. 16).

Por isso, a Lei 10.639/03, tras a luta do movimento negro, promulgada com o objetivo principal de instituir o ensino de História da África e Cultura Afro-Brasileira na educação brasileira. Foi com base na desvalorização de tais estudos que 0 movimento negro apontou para a necessidade de diretrizes com o intuito de orientar projetos na formulação de projetos empenhados na valorização da história e cultura de tanto dos afro-brasileiros quanto dos africanos. Para assim haver a prática de uma educação comprometida de maneira positiva com as relações étnico-raciais, considerando possuir em seus currículos conteúdos associados ao reconhecimento e valorização de tal história e cultura, assim como a diversidade da nação brasileira. E, principalmente a igualdade no direito a uma educação de qualidade que seja capaz de permitir ao negro seu reconhecimento na cultura nacional.

Considerando o estudo da diversidade étnico racial em relação ao respeito das diferenças existentes na nossa sociedade os PCNs, na idealização de uma educação mais democrática, indicam como objetivos do Ensino Fundamental que os alunos sejam capazes de "conhecer e valorizar a pluralidade do patrimônio sociocultural brasileiro, bem como aspectos socioculturais de outros povos e nações, posicionando-se contra qualquer discriminação baseada em diferenças culturais, de classe social, de crenças, de sexo, de etnia ou outras características individuais e sociais" (Brasil, 1997, p. 69).

A partir desse reconhecimento ocorreu uma certa valorização, divulgação e respeito aos processos históricos ocorridos durante a resistência negra, iniciada pelos africanos escravizados em nosso país e continuada através de seus descendentes. Por isso, a Lei 10.639/03, na incessante busca desse reconhecimento, deu continuidade na edificação de um ensino democrático capaz de incorporar não somente a história, mas sobretudo a dignidade de todos os povos que participaram da construção da nação.

A educação brasileira é baseada na cultura eurocêntrica, por isso, por muito tempo desenvolveu uma política de discriminação e exclusão do povo negro ao não inserir nos conteúdos programáticos estudos sobre essa cultura. Na formação histórica do Brasil o negro foi mantido à margem da sociedade brasileira. Tal desigualdade racial pode ser observada também no ambiente educacional, visto que mesmo após a Lei 10.639 diversos materiais didáticos trabalhados na escola não possuam aspectos 
capazes de contribuírem para 0 desenvolvimento da prática de valorização das culturas e etnias diferentes que existem em nosso País.

Assim, muitos discursos impressos no currículo escolar foram desenvolvidos para destacar algumas formas de vida e de cultura de alguns grupos, mas infelizmente deturpando outras, impresso nos livros didáticos e outras pela própria omissão dos conhecimentos de vida do negro enquanto formador da nação brasileira, o qual é sempre associado à dualidade escravidão/mão de obra livre. Tal dualidade causa a simplificação e até mesmo redução da contribuição cultural dessa categoria social.

Outro fator ainda a polaridade social básica da economia açucareira 0 senhor de engenho e o escravo uma vez plasmada como forma viável de coexistência, constituiria uma matriz estrutural que, adaptada a diferentes setores produtivos, possibilitaria a edificação da sociedade brasileira tradicional" (Ribeiro, 2006, p. 275). O que o sociólogo Darcy Ribeiro chama de povo brasileiro e responsável pela contribuição na das matrizes étnicas formadoras da nação brasileira não foi incorporado nos livros didáticos de História, pois na maioria das vezes o componente negro é referenciado somente como mão-de-obra escrava sem participação efetiva no discurso.

De acordo com Kabengele Munanga a escravidão no Brasil relaciona-se com uma produção discursiva cheia de estereótipos e preconceitos, ambos incorporados a uma situação de violento equilíbrio onde prevalece a relação dominante dominado. A desvalorização e a alienação do negro estende-se a tudo que toca a ele: 0 continente, os países, as instituições, o corpo, a mente, a língua, a música, a arte, etc. Seu continente é quente demais, de clima viciado, malcheiroso, de geografia tão desesperada que o condena à pobreza e à eterna dependência. 0 ser negro é uma degeneração devido à temperatura excessivamente quente (Munanga, 1988, p. 21).

Assim, historicamente a imposição dos valores europeus ao restante do mundo foram apoiados na violência apontada durante a colonização para que fossem implantados. E, além de configurarem os povos subjugados como elementos neutros da própria história, considerava-os somente como mão-de-obra na produção e abastecimento da riqueza europeia.

No final da década de 80 Ana Célia da Silva publicou a pesquisa "Estereótipos e preconceitos em relação ao negro no livro de Comunicação e Expressão de $1^{\circ}$ grau, nivel 1" onde, após analisar 82 livros de Língua Portuguesa relata que as ilustrações e textos remetem aos seguintes estereótipos:

a) negros rejeitados explicitamente: apareciam como criança negra barrada", "castigada", "faminta", "isolada", "em último lugar";

b) exercendo atividades subalternas: doméstica, trabalhador braça, escravo;

c) considerado minoria;

d) incapaz: burro, ingênuo, desatento, desastrado, inibido;

e) sem identidade: sem nome, sem origem;

e) pobre: maltrapilho, favelado, esmoler;

f) estigmatizado em papéis sociais especificos: cantor, jogador de futebol; 
g) desumanização do negro: associado o objeto, a formiga, a burro a macaco (Silva, 2002, p. 37).

As imagens e textos sobre os negros nos livros didáticos permitem que se estabelecesse uma associação entre a baixa-auto-estima dos alunos negros e as imagens dos negros registradas nesses livros. Uma vez que o livro didático caracteriza-se por ser um instrumento que compõe a cultura escolar, por isso causa e transmite sentimentos, significados, saberes e valores aos seus respectivos leitores.

Pode ser verificado que diversos livros didáticos associaram imagens negativas $\mathrm{e}$ depreciativas do negro no Brasil, imagens as quais podem contribuir de maneira negativa na formação de crianças e adolescentes negros que, ao visualizarem as imagens não conseguem a identificação com os antepassados. De tal maneira, o livro didático pode ser visto como meio de transmissão de discriminação e preconceito, pois ao desconsiderar o processo histórico, a cultura e as experiências cotidianas dos negros contribui para excluí-los tanto da história quanto da sociedade.

Darcy Ribeiro relata que: Examinando a carreira do negro no Brasil se verifica que, introduzido como escravo, ele foi desde o primeiro momento chamado à execução das tarefas mais duras, como mão-de-obra fundamental de todos os setores produtivos. Tratado como besta de carga exaurida no trabalho, na qualidade de mero investimento destinado a produzir o máximo de lucros, enfrentava precaríssimas condições de sobrevivência. Ascendendo à condição de trabalhador livre, antes ou depois da abolição, o negro se adaptando a novas formas de exploração que, embora melhores que a escravidão, só lhe permitiam integrar-se na sociedade e no mundo cultural, que se tornaram seus, na condição de um subproletariado compelido ao exercício de seu antigo papel, que continuava sendo principalmente o de animal de serviço (Ribeiro, 2006, p. 232).

Percebe-se que desde a chegada do negro em nosso País ocorre o esforço por parte do colonizador em buscar justificativas para a existência da escravidão assim como para tentar tornar aceita a opressão e marginalização do negro, a qual ocorre diante da desvalorização imposta em situações que os submetem a desvalorização. $\mathrm{Na}$ obra Capitalismo e Escravidão no Brasil Meridional, Fernando Henrique Cardoso relata que o papel do escravizado na sociedade brasileira "como ser desprovido de raciocínio, ou de qualquer sentimento humano. Incapaz de criar ou produzir por conta própria (...) o escravo era uma "coisa", sujeita ao poder e à propriedade de outrem, e, como tal, "havido por morto", privado de todos os direitos e sem representação alguma" (Cardoso, 2003, p. 87). 0 autor deixa explicita as ocorrências de diferenças sociais e raciais impostas pela sociedade escravista, assim como a dificuldade de integração do negro no pós-abolição.

Cleyton Rodrigues dos Santos relata que "de fato é sabido que, inicialmente, a economia cafeeira foi calcada em pilares baseados no latifúndio monocultura e na mão-de-obra escrava. No entanto, no decorrer da substituição do escravo pelo trabalhador, foi inserido o imigrante" (Santos, 2003, p. 7). Apesar do processo de 
imigração ter iniciado antes da abolição fica claro o objetivo de impedimento da entrada do negro no mercado de trabalho, tendo como consequência o impedimento de sua estabilidade civil, econômica e até mesmo sua condição de cidadão.

De acordo com a classe dominante, o negro era desprovido de competência para exercer atividades que tinham maior valor social, por isso tais atividades deveriam ser realizadas pelos emigrantes brancos que também tinham a função de miscigenar o País. Assim, o processo de arianização do brasileiro avançava diariamente e "já com um oitavo de sangue negro, a aparência africana se apaga por completo (...) e assim o negro desaparece aos poucos, dissolvendo-se até a aparência de ariano puro" (Prado, 1996, p. 191). No entanto tal processo fracassou, uma vez que não necessariamente a união de mestiços de pele clara com negros garante descendentes mais claros. Como consequência tal mistura acarretou na falta de identidade para esses descendentes, assim como ausência de reconhecimento para com a sua cor e os seus ancestrais.

Quando os livros didáticos apresentam ilustrações e textos com imagens distorcidas e estereotipadas dos negros contribuem na desqualificação desses grupos sociais e também estimulam preconceitos, pois geram referencias negativas capazes de provocar até mesmo a baixa autoestima. Assim como ao permitir o emudecimento diante da presença e contribuição dos negros na sociedade brasileira coopera com a situação de propiciar a anulação e exclusão social de uma parcela significativa da nossa população.

Infelizmente, por diversas vezes, ocorre a propagação de discursos preconceituosos e errôneos nos livros didáticos em relação aos assuntos vinculados à História da África e dos Africanos. Um deles retrata a ideia de que os negros são uma raça inferiorizada, com a cultura desprezada e povos a-históricos. 0 outro discurso relaciona-se a História do Brasil, pois mesmo após 300 anos de escravidão africana os negros não puderam ser considerados livres, considerando que não houve uma integração efetiva dos mesmos na sociedade. Considerando as representações dos negros no livro didático associadas a uma ideologia do grupo dominante. Os alunos negros não estudam sua própria história e por vezes enxergam os sujeitos negros como atores que desempenham papéis sociais subalternos e desvalorizados no contexto social.

Por isso Silva comenta que "o estereótipo do negro estigmatizado em papéis de baixo prestígio social contribui, em grande parte, para que as pessoas de pele clara tenham adquirido o senso comum de que os negros não têm papéis e funções diversificadas e que esse é o "seu lugar" na sociedade, bem como para que muitos negros no passado interiorizassem essa representação e aceitassem como natural a estigmatização, como o seu lugar na sociedade. Por outro lado a exclusão real na sociedade é exercida através do código da "boa aparência", que contribui em larga escala para barrar os negros que tem capacitação, para exercer os papéis e funções consideradas de prestígio social" (Silva, 2001, p. 14). 
Diante disso, a ideia da diversidade brasileira e da contribuição que as etnias trouxeram ao país, foram inseridos nos Parâmetros Curriculares Nacionais, incentivando assim a valorização das influências dos povos que participaram da formação da sociedade brasileira, de forma a reconhecer sua autenticidade, para que o ideal democrático de que todos tenham direito à dignidade e liberdade enquanto cidadãos faça parte dos conteúdos escolares, pois "recuperar as origens das diversas influências é valorizar os povos que as trouxeram e seus descendentes, reconhecendo suas lutas pela defesa da dignidade e da liberdade, atuando na construção cotidiana da democracia no Brasil, dando voz a um passado que se faz presente em seres humanos que afirmam e reafirmam sua dignidade na herança cultural que carregam" (1997, p. 154).

Assim, Darcy Ribeiro relata que a contribuição do negro gerou o que há de mais vigoroso e belo na cultura popular brasileira. De acordo com ele: Com base nela é que se estrutura o nosso Carnaval, o culto de lemanjá, a capoeira e inumeráveis manifestações culturais. $O$ negro aproveita cada oportunidade que lhe é dada para expressar o seu valor (...) como é o caso da música popular, do futebol e de numerosas formas de competição e expressão. 0 negro vem a ser, por isso, apesar de todas as vicissitudes que enfrenta, o componente mais criativo da cultura brasileira e aquele que, junto com os índios, mais singulariza o nosso povo (Ribeiro, 2006, p. 222).

Ao atuar na sala de aula os professores devem estar atentos ao conteúdo dos livros didáticos em relação à interpretação dos assuntos a serem abordados. $E$, ao trabalhar com material didático mal elaborado o profissional deve ser capaz de reverter de maneira positiva as informações disponibilizadas. Ao identificar um aspecto estereotipado do negro o professor deve, no mínimo, realizar uma leitura crítica junto a seus alunos.

Podendo também, de acordo com o assunto discutido inserir atividades relacionadas a personagens negros que, de acordo com Darcy Ribeiro: Participando biológica e socialmente do mundo branco, pode acercar-se melhor de sua cultura erudita e nos deu algumas figuras mais dignas e cultas que tivemos nas letras, nas artes e na política. Entre eles, o artista Aleijadinho; o escritor Machado de Assis; o jurista Rui Barbosa; o compositor José Maurício; o poeta Cruz e Sousa; o tribuno Luís Gama; como políticos, os irmãos Mangabeira e Nelson Carneiro; e como intelectuais, Abdias do Nascimento e Guerreiro Ramos (Ribeiro, 2006, p. 223).

Deve ser lembrado que, na realidade de muitas famílias o livro didático pode ser considerado como, às vezes, a única fonte de acesso à leitura e ao conhecimento. Por isso é necessária uma interpretação correta da representação negra no material nas aulas dos docentes, pois essas atividades permitem aos alunos a capacidade de reinventarem-se, transformarem-se e adaptarem-se para trilharem um futuro positivo.

De acordo com os valores da democracia, o papel mais importante desempenhado pela educação escolar no Brasil vem a ser o da inclusão. Diante de tantas desigualdades existentes em nosso País, destaca-se as diferenças em 
oportunidades ao acesso e permanência na escola assim como as consequências dessas dificuldades no ingresso ao mercado de trabalho formal. E, mais uma vez os indicadores socioeconômicos apontam que a exclusão tem cor, uma vez que as taxas de desemprego, analfabetismo e evasão escolar são encabeçados pelos negros.

\section{3.-Metodologia.}

Considerando a análise documental o presente estudo se fundamentou no método qualitativo do tipo descritivo fazendo uma reflexão em torno das bibliografias e referências dos teóricos propostos acerca do assunto. Os instrumentos para a coleta dos dados se deu através da observação das situação proposta pelas imagens fonte específica dos livros e de como os exemplos apresentados influenciaram no comportamento da proposta apresentada.

Com relação à teoria o intuito de associar as concepções semióticas aos conceitos e definições indicadas pelas imagens permitem maiores possibilidades de aprofundamento e entendimento do contexto apresentado. Como ponto essencial do trabalho destaca-se a discussão da representação da escravidão negra através das imagens disponibilizadas em livros didáticos.

A metodologia do trabalho orientou-se basicamente pelos seguintes passos:

- Levantamento, análise e reflexão em torno das bibliografias relacionadas ao assunto discutido;

- Triagem de livro didático dos $6^{\circ} \mathrm{s}$ anos do ensino fundamental para observação das imagens;

- Seleção de imagens associadas ao tema proposto para realização das análises de acordo com o tema proposto.

Cada uma das fases foram evoluindo no transcorrer da pesquisa e são capazes de demonstrar que tanto a parte teórica quanto a análise das imagens foram fatores essenciais para a levantamento das questões principais, respostas e também resultados.

\section{4.- Discussão dos resultados: Análise das Imagens}

Tradicionalmente o livro didático tem seu lugar nas escolas brasileiras, caminhando por décadas como importante instrumento de apoio ao trabalho do professor e como referência ao ensino aprendizagem dos alunos matriculados na rede de ensino privado e público. 0 livro didático influencia diretamente na prática docente do professor, pois explicita e sistematiza os conteúdos históricos oriundos das propostas curriculares e da produção historiográfica. Nesse sentido, a autora Circe Bittencourt em seu livro: Ensino de História: fundamentos e métodos, salienta que "o livro didático tem sido o principal responsável pela concretização dos conteúdos históricos escolares" (Bittencourt, 2004, p. 313). Nessa condição, o livro didático tornasse importante recurso básico do trabalho docente no processo de ensino/aprendizagem 
por englobar os conteúdos históricos e além disso fornecer, organizar e sistematizar os conteúdos.

O livro utilizado para análise foi o de História dos $6^{\circ} \mathrm{s}$ anos do Ensino Fundamental "Estudar História: Das origens do homem à era digital". Autora Patrícia Ramos Braic, 1. ed. (2011)". A escolha se deu de forma intencional, por ser um livro muito atrativo, que propicia um embasamento mais crítico dos alunos, sendo o mais diversificado como fonte de conhecimento. Tal livro contempla ilustrações, dos negros Africanos Portugueses e índios com suas culturas, muitas imagens que ilustram os textos, e os conteúdos contempla várias interpretações. Dessa forma as imagens contribuem para a compreensão do conteúdo e principalmente para as análises, interpretações bem como, para novas concepções com grande representatividade para 0 conhecimento sobre 0 assunto estudado.

De acordo com as últimas estatísticas do Fundo Nacional de Desenvolvimento da Educação (FNDE) o livro História, Sociedade \& Cidadania consta na lista dos mais comprados pelo Estado brasileiro.

A tabela 1 demonstra que no ano de 2014 foram adquiridas 3.330 .040 unidades do respectivo livro didático através do Programa Nacional do Livro Didático (PNLD).

\begin{tabular}{|c|c|c|c|c|}
\hline Título & Tipo & Qtde & Cad & Quantidade \\
\hline História, Sociedade \& Cidadania - $6^{\circ}$ Ano & L & 320 & 21 & 909.106 \\
\hline História, Sociedade \& Cidadania - $6^{\circ}$ Ano & $\mathrm{M}$ & 448 & 29 & 17.432 \\
\hline História, Sociedade \& Cidadania - $7^{\circ}$ Ano & $\mathrm{L}$ & 320 & 21 & 834.345 \\
\hline História, Sociedade \& Cidadania - $7^{0}$ Ano & $\mathrm{M}$ & 448 & 29 & 16.561 \\
\hline História, Sociedade \& Cidadania - $8^{\circ}$ Ano & L & 320 & 21 & 779.878 \\
\hline História, Sociedade \& Cidadania - $8^{\circ}$ Ano & $M$ & 448 & 29 & 16.056 \\
\hline História, Sociedade \& Cidadania - $9^{\circ}$ Ano & L & 336 & 22 & 740.717 \\
\hline História, Sociedade \& Cidadania - $9^{\circ}$ Ano & $\mathrm{M}$ & 464 & 30 & 15.945 \\
\hline
\end{tabular}

Fonte: Livro Didático, dados Estatísticos FNDE (2017, p. 7).

Deste modo, a utilização das imagens iconográficas no ensino de História consiste numa importante ferramenta pedagógica na construção do conhecimento histórico pelos alunos. No entanto, a imagem é uma representação da vida cotidiana que busca retratar a realidade e é por meio dela que o artista expressa os valores representados de uma época, seja passado ou presente, num dado contexto histórico.

França Paiva aponta alguns aspectos metodológicos relacionados ao trabalho do historiador com as imagens. Segundo o autor "o que se verá é que, por vezes. Pequenos detalhes podem significar chaves para exames aprofundados; que comparações entre imagens e entre elas e outros documentos podem revelar aspectos camuflados dessa história; que porções importantes dessa realidade passada estão apenas sugeridas nessas imagens e que elas nunca vêm com uma 
espécie de legenda definitiva, por meio da qual o leitor, seja qual for sua época, poderá lê-las e compreendê-las" (Paiva, 2009, p. 55).

\section{1.-Descrição da $1^{\mathrm{a}}$ figura.}

Primeiro capítulo "O Nordeste Açucareiro" Braic (p. 244-257) se visualiza um lugar montanhoso, vários casarões no alto, abaixo uma grande indústria de açúcar. É possivel visualizar muitos negros carregando cestos as costas, braçadas de cana de açúcar, e ou fazendo os mais variados trabalhos. Enquanto os senhores portugueses Observando, vigiando e ou fiscalizando o trabalho executado.

Neste capítulo percebeu-se a existência de estereótipos e preconceitos no que se refere aos negros, pois ao analisar as ilustrações que acompanham os textos podese observar que as mesmas apresentam uma grande divisão social baseada na estrutura econômica, a dualidade ao considerar os senhores de engenho e os escravos. Sendo que, os negros são apresentados sempre como escravos; não sendo apresentadas as outras composições sociais (libertos e forros).

\section{2.-Descrição da $2^{a}$ figura.}

No segundo Capítulo Braic (2011, p. 251- 252) mostra o "engenho" uma plantação de cana de açúcar: Negros cortando, limpando, empilhando e carregando no braço os feixes de cana de açúcar enquanto, capitães de chicote as mãos dando ordens e ou açoitando os negros durante seu trabalho e em outro momento os negros carregando sacas de açúcar já fabricado por eles a casa dos senhores. Nesta figura mostram-se quem fazia parte da estrutura e da logística enquanto estrutura em função da produção da cana-de-açúcar."

Durante a descrição encontramos o seguinte trecho, que em nenhum momento cita as acomodações dos negros: A residência do senhor de engenho e de sua família era a casa-grande. Ela podia ser térrea ou assobradada, funcionando também como fortaleza, hospedaria para visitantes e centro administrativo do engenho.

Assim sendo, a imagem demonstra os negros realizando trabalho agrícola na lavoura de cana-de-açúcar. No entanto, estão sob a vigilância de um feitor montado a cavalo com um chicote na mão, representado repressão em relação aos trabalhadores. Ainda para reforçar a violência exercida pode ser identificado um negro segurando uma lança na mão.

Ainda, é possível reafirmar a situação de trabalho árduo e constante era exercido tanto por homens quanto por mulheres negras. Como a execução de trabalhos braçais considerados penosos ou inadequados não eram relacionados às pessoas brancas, as mesmas nem aparecem na imagem. "O engenho de açúcar" destaca a produção do açúcar realizada pelos escravos, a qual ocorria na maioria das situações sob a direção do mestre de açúcar e do feitor. Pode ser observado que os escravos movimentavam-se bem próximos as fornalhas e caldeiras, ficando expostos a riscos de queimaduras e também a calores elevados. 
Assim sendo, os livros didáticos dos $6^{\circ}$ s anos do ensino fundamental, confirmam a imagem de inferioridade a qual é dada aos negros no período colonial unicamente "escravo", não permitindo que sejam realizadas outras discussões sobre as outras experiências que nos negros tiveram no Brasil como, por exemplo, quais eram as formas que os mesmos utilizavam para adquirirem a respectiva alforria. Segundo Souza "a obtenção da carta de alforria poderia ocorrer por meio da compra (alforrias onerosas pagas), por meio de realização de condições (alforrias condicionais) imposta ao escravo por um determinado tempo, ou ainda poderiam ser conseguidas gratuitamente" (Souza, 2014, p. 3).

\section{3.-Descrição da $3^{a}$ figura.}

Nesta figura observa-se a venda de uma escravo um comercio lucrativo, o negro ao meio sendo tocado por dois senhores enquanto verificam os dentes, o corpo físico como músculos, se é forte o suficiente para o trabalho. Ao lado grandes tachos de caldo de cana efervescente, os negros mexendo sem parar para apurar o açúcar. Quando pronto encaminhado a outros negros para mexerem até estar pronto para 0 consumo e ou a venda.

Contudo, a "negociação a venda de escravos um comércio lucrativo na época" onde "o senhor de engenho verifica a idade e as condições de saúde do escravo antes de comprá-lo" (Braic, 2011, p. 253). Ainda, a "Casa de Plantador" com a visualização da realização do beneficiamento da cana-de-açúcar, atividade realizadas pelas diversas famílias que viviam ao redor dos engenhos e trabalhavam como arrendatários. Novamente a participação do negro aparece somente na condição de escravo, realizando atividades que exigem esforço físico.

\section{4.-Descrição da $4^{a}$ figura.}

Neste capítulo Braic (p. 256) apresenta negros reunidos, dentre eles homens mulheres com crianças amarradas com panos junto ao seu corpo. Se visualiza os negros batendo em pedaços de madeira, batendo palmas e dançando num terreiro bem próximo a um grande casarão.

Nesta figura o "Batuque" representava a reunião de escravos na tentativa de preservarem suas identidades africanas através de música e danças. De acordo com o próprio texto do livro didático "muitas vezes, a resistência era disfarçada numa aparente acomodação ao cativeiro.

As imagens apresentadas revelam a omissão de conhecimentos do povo negro enquanto grupo social formador da nação brasileira, pois, associa-os sempre nas atividades de trabalho escravo. Ainda, as imagens explicitas nos livros didáticos dos $6^{\circ}$ anos do ensino fundamental, denotam claramente a classificação do negro como ser inferior. Cabe aos docentes redefinirem o trabalho junto aos alunos, a fim de valorizar as diferenças como um aspecto positivo na formação social do aluno. No entretanto, livro didático na sala de aula é um desafio para o professor, pois, se faz 
necessário compreender que "os livros didáticos podem difundir imagens agressivas sobre o povo brasileiro e, ou outros povos" (Villalta, 2001, p. 4) atribuindo significados, estabelecendo relações com o sistema de interesse: cultural, econômico, político e social.

\section{5.-Conclusão.}

Nesta pesquisa pode-se verificar que mesmo após a Lei 10.639 ainda encontramos em livro didático a negação de presença, participação e contribuição da população negra na construção da sociedade brasileira, ocorrendo uma distorção e estigmatização nos textos e imagens sobre os negros, deste modo, alunos negros podem se apropriar do sentimento de não pertencer a tal sociedade. Quando não são encontrados referencias positivas, podendo ainda sentir-se inferiores ou até mesmo desistirem de frequentar a escola.

Ao analisar o capítulo do livro didático dos $6^{\circ} \mathrm{s}$ anos do ensino fundamental, possibilitou-nos uma visão de preocupação quanto a história dos negros, de maneira a superar a imagem cristalizada e única do negro como (serviçal escravidão). A abordagem poderia valorizar com mais intensidade 0 reconhecimento das culturas negras, para diminuir, assim as distorções e os estigmas.

Assim sendo, o profissional de educação deve se apropriar de recursos para demonstrar que a diversidade é capaz de formar um mosaico humano com características belas e únicas. Por isso, o educador deve trazer para a sala de aula evidências, destaques e realização de trabalhos que enfoquem o resgate cultural do povo que, com a história violentada, ainda, perpassa por consequências afligindo de maneira considerável seus descendentes. Deste modo, os livros didáticos devem ser observados para que sejam instrumentos de liberdade e solidariedade, além do conhecimento.

Um destaque relevante a cultura negra foi a implementação da Lei 10.639 está se colocou como um avanço na transformação positiva na representação do negro no livro didático, no entanto muito ainda deve ser feito para que cada vez mais a figura do negro seja incluso na escola e na sociedade como um todo.

No entanto, deve-se observar que ainda nos livros de História, as imagens e textos demonstram a história brasileira a partir da participação dos chamados heróis nacionais que geralmente são homens brancos. De tal maneira, o negro como o índio possuem participação reduzida neste processo histórico. Quando aparecem em livros didáticos em textos e ou ilustrações, são retratados ainda de forma pejorativa, preconceituosa e ou estereotipada.

\section{6.- Bibliografía.}

Agualusa, J.E. (2004). O Vendedor de Passados. Rio de Janeiro: Gryphus. 
Azevedo, E.L.A. (2011). Imagens de Escravidão Negra no Livro Didático de História após a Lei 10.639/03. In: XI Congresso Luso Afro Brasileiro de Ciências Sociais. Diversidades e (Des)igualdades. Salvador: Universidade Federal da Bahia (UFBA), 07 a 10 de agosto.

Bittencourt, C.M.F. (2004). Ensino de História: fundamentos e métodos. São Paulo: Cortez.

Braic, P.R. (2011). Estudar História: das origens do homem à era digital. $1^{0} \mathrm{ed}$. Obra em 4 Volumes para alunos do $6^{\circ}$ ao $9^{\circ}$ ano. São Paulo: Moderna.

Cardoso, F.H. (2003). Capitalismo e escravidão no Brasil Meridional. São Paulo: Saraiva.

Faria, P.S., Hollerbach, J.D'.G., Herneck, H.R. (2011). Trabalho, política e formação humana: desafios e tendências da formação profissional em defesa do público. Belo Horizonte: VI Simpósio sobre Trabalho e Educação.

Fernandes, J.R.O. (2005). Ensino de história e diversidade cultural: desafios e possibilidades. Cadernos Cedes, Campinas: UNICAMP, v.25, n.67, p.378388.

Livro Didático. (2017). Programa do livro didático FNDE. Recuperado de: http://www.fnde.gov.br/programas/livro-didatico/livro-didatico-dadosestatisticos.

Júnior, A. B. (2011). História, Sociedade \& Cidadania. $6^{\circ}$ ano. Disciplina: História Ensino Fundamental. São Paulo: Saraiva.

Ministério da Educação, Secretaria de Educação Continuada Alfabetização e Diversidade. (2005). Educação antirracista, caminhos abertos pela Lei Federal $n^{0} 10.639 / 03$. Secretaria de Educação Continuada, Alfabetização e Diversidade. (Coleção Educação para todos). Brasília: MEC.

Munanga, K. (1998). Negritude. Usos e Sentidos. São Paulo: Editora Ática.

Paiva, E.F. (2009). História \& Imagens. 2. ed. Belo Horizonte: Autêntica.

Prado, P. (1996). Retrato do Brasil, org. Carlos, A.C, 8.ed. São Paulo: Companhia das Letras.

Ribeiro, D. (2006). O povo brasileiro: A formação e o sentido do Brasil. São Paulo: Companhia das Letras. 
Santos, C.R. (2003) Da Escravidão a Imigração: a Transição do Trabalho Escravo para o Trabalho Livre Assalariado no Brasil. São Paulo: Revista Intertemas Sociais. V.6, n.6, p.7-10.

Secretaria de Educação Fundamental. (1997) Parâmetros curriculares nacionais: Introdução aos parâmetros curriculares nacionais. Secretaria de Educação Fundamental. Brasilia: MEC.

Silva, A.C. (2001). Desconstruindo a discriminação do negro no livro didático. Salvador: EDUFBA.

Silva, J.H. (2002). Discriminação Racial nas Escolas: entre a lei e as práticas sociais. Brasilia: UNESCO.

Villalta, L.C. (2001). O livro didático de História no Brasil: perspectivas de abordagem. São Paulo: Revista de Pós-Graduação em História. v.9, n.2, p.04. 